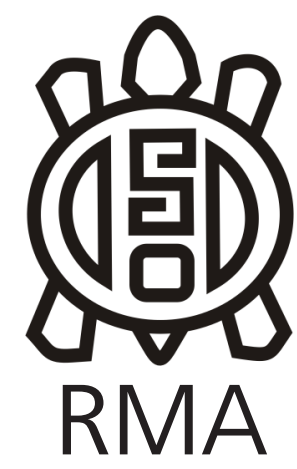

Arqueología

\title{
Arqueología: la pelea por el nombre
}

\author{
Archaeology: the fight for the name
}

Vivian Scheinsohn*

* CONICET, Instituto Nacional de Antropología y Pensamiento Latinoamericano. Facultad de Filosofía y Letras (UBA), Argentina. E-mail: vscheinsohn@yahoo.com

\begin{abstract}
Resumen
Desde hace unas décadas viene dándose una callada disputa respecto del término arqueología en el ámbito de las Humanidades y las Ciencias Sociales. En este trabajo revisaré la historia de ese términopara identificar cuáles fueron sus usos, su nivel de relación, si la hubo, con la práctica arqueológica que les fue contemporánea, y cómo han impactado estos usos en la percepción de la arqueología como disciplina en el ámbito académico. Los objetivos de un trabajo de estas características son, por un lado, aportar una guía que permita conocer cómo surgió esa disputa y, por el otro, aportar una herramienta que permita, a quienes trabajamos en el oficio de la arqueología, intervenir en la misma y poder cambiar nuestra relación con el resto de las disciplinas académicas. Para lograr estos objetivos es menester hacer un recorrido por el pensamiento occidental de los últimos siglos
\end{abstract}

Palabras Claves: Arqueologia; Pensamiento occidental; Filosofía; Poscolonialismo; Metáfora.

\begin{abstract}
For some decades there has been a silent argument regarding the term archaeology in the field of Humanities and Social Sciences. In this paper I will review the history of the termto identify those uses, their level of relationship, if any, with the archaeological practice that was contemporary to them and how these uses have impacted on the perception of Archaeology as a discipline in the academic field. The goal of a work of these characteristics is twofold: on the one hand, to provide a guide that allows us to know how this argument arose and, on the other, to provide a tool that allows those who work in the archaeology profession to get involved in it and to be able to change our relationship with the rest of theacademic disciplines. But to achieve these goals, it would be necessary to take a tour around the last centuries of the Western thought.
\end{abstract}

Key words: Archeology; Western Thought; Philosophy; Postcolonialism; Metaphor.

En el capítulo introductorio a su libro Reclaiming Archaeology, el arqueólogo español Alfredo González Ruibal (2013:1) refiere haber hecho una búsqueda en Google Scholar del término arqueología. Los primeros tres resultados que obtuvo lo refirieron a Foucault. Así, se podría decir que casi enojado,considera que "la disciplina ha sido tratada de manera superficial como un mero proveedor de metáforas que otros intelectuales han explotado" (González Ruibal2013:1, traducción mía). Según mi experiencia, si se usa Google, antes que Google Scholar, recién luego de recorridas diez páginas comienzan a aparecerlas referenciasa Foucault. En todo caso, ambas experiencias describen adecuadamente los dos polos entre los que se mueve la arqueología: por un lado el archaeo-appeal (Holtorf 2005) ya instalado en la cultura popular contemporánea (y de ahí, el predominio en Google) y por el otro la disputa por el nombre disciplinar con la filosofía. Pero en el ámbito de la arqueología, esta disputa, objeto de este trabajo, apenas fue registrada por lo que muchos desconocen su origen y como se llego a la situación actual.

Para poder entender el porqué de esta disputa, revisaré la historia del uso del término "arqueología"a fin de poder identificar cuáles fueron sus usos, sus correlatos -si los hubo- con la práctica arqueológica que les fue contemporánea y cómo ha impactado ese uso en la percepción de la arqueología en el ámbito académico.El objetivo de un trabajo de estas características es, por un lado, aportar una guía que permita conocer cómo surgió este malentendido y, por otro,generar una herramienta que nos permita, a quienes trabajamos en el oficio de la arqueología, cambiar nuestra relación con el resto de las disciplinas. Para lograr estos objetivos, entonces, primero me concentraré en el surgimiento de la arqueología como disciplina, para luego sobrevolar el pensamiento social de los últimos siglos. 


\section{El surgimiento de la arqueología como disciplina}

Arqueología, etimológicamente, viene del griego ả $\rho \alpha$ aío, (archaío) que quiere decir viejo o antiguo, y $\lambda$ ó$_{0} \sigma$, (logos), ciencia o estudio. Así, la etimología de la palabra remite a una ciencia de lo antiguo o del origen. Claro, la arqueología estudiaba cosas viejas. Pero en verdad, en la actualidad, el acento está más puesto en las cosas que en su antigüedad. La disciplina se sustenta en la especial relación que los humanos tenemos con los objetos que usamos y que hacemos. Como especie animal, esto no nos hace originales (por ejemplo, están quienes hablan de una arqueología primate, ver Haslam et al. 2009 y algo similar podría plantearse para el caso de los cuervos de Nueva Caledonia). Pero los humanos hemos llevado esta relación a niveles novedosos.De allí, la necesidad de una disciplina que permita estudiar esa relación en términos espaciales y temporales.

Según Daniel (1967), existen dos arqueologías distintas. La primera surgió durante el Renacimiento,focalizada en la antigüedad griega, romana y bíblica. ${ }^{1}$ Hacia el inicio del siglo XVII el estudio filológico de los documentos de la antigüedad parecía haber llegado a un punto muerto por lo que los especialistas comenzaron a dedicarse a la recolección de evidencia material. A quienes se abocaron a esa tarea se los comenzó a llamar "anticuarios" (Trigger 2006). Entre los primeros exponentes del anticuarismo se encuentran el italiano Francesco Bianchini y el alemán Johann Winckelmann. Si bien Winckelmann es frecuentemente identificado como el fundador de la arqueología clásica (por haber demostrado que era posible establecer una cronología de estilos de estatuas que pudiera aplicarse a aquellas no datadas) sólo se interesaba, al igual que la mayoría de los otros anticuarios contemporáneos, por los objetos sin contemplar su contexto. Durante el siglo XVII también se desarrollaron las primeras excavaciones en Herculano y Pompeya lo que contribuyó a transformar el anticuarismo en la naciente arqueología clásica (Trigger 2006). La segunda corriente observada por Daniel (1967) surge en el siglo XIX, como parte de la historia natural, focalizada en los orígenes humanos y en los pueblos considerados "exóticos". Fue llamada arqueología prehistórica (Trigger 2006).

Para ambas, la excavación se convertirá pronto en una cabecera de playa disciplinar. Como señala González Ruibal: "Los arqueólogos han sido los primeros en desarrollar una metodología para sacar conocimientos de la tierra y todos los que hacen eso (antropólogos o científicos forenses) lo han aprendido a hacer, en última instancia, a partir de la arqueología."(González Ruibal 2013:8)². La noción de las capas estratigráficas

\footnotetext{
1 En este trabajo la arqueología clásica será considerada como la arqueología que se refiere a estos períodos

2 Todas las traducciones son mías excepto en el caso de los textos que figuran en la bibliografía en castellano. En la medida en que pude hacerlo, traté de consultar los textos en el idioma original pero mi
}

como contenedoras de artefactos pasó a dominar la arqueología del siglo XX, convirtiendo a la excavación en su metodología por antonomasia (Thomas 2009).

Así, la arqueología, como disciplina, se desarrolla encarnando y condensando la condición moderna, a partir de tres ideas: la de que se puede crear nuevo conocimiento a partir de las cosas, la de que el pasado difiere del presente y la de que la tradición y el mito no son fuentes adecuadas de información sobre el pasado (Thomas 2004). De allí que el surgimiento de los estados-nación modernos y su necesidad de legitimación impulsaran las investigaciones arqueológicas. Por otro lado, en el sigloXVIII surge la noción de que,bajo las apariencias externas, se ocultan estructuras más profundas. Este cambio coincidió con la transformación del anticuarismo en arqueología, por lo que Thomas (2009) argumenta que la "revolución estructural" fue contemporánea a la "revolución estratigráfica".Ahora bien, mientras la arqueología se define como disciplina y toma nombre propio en Europa, apartándose de la historia natural y la del arte, también surge una "arqueología" en el ámbito filosófico.

\section{La arqueología filosófica}

Aunque el uso del término arché puede remontarse a Aristóteles, el primero en usar el término "arqueología"en el ámbito filosófico fue Immanuel Kant. En 1790 dice:

"(...) Aquí, el arqueólogo de la naturaleza tiene la libertad de volver a las huellas que quedaron de las primeras revoluciones de la naturaleza y, apelando a todo lo que conoce puede conjeturar sobre su mecanismo, puede rastrear la génesis de esa gran familia de los seres vivos (porque debe ser representada como una familia si la ya mencionada afinidad, coherentemente consistente, tiene algún fundamento)" (Kant 2007:248, cursivas mías)

Es notorio que al referirse a la "gran familia de los seres vivos" y sus afinidades, Kant está anticipando una visión darwiniana en tanto sostieneque todos los seres vivos estarían ligados por relaciones de ancestralidad. Pero, aquí me interesa más la idea del "arqueólogo de la naturaleza". En una nota a pie de página la aclara:

"Si el nombre historia natural, ahora que se adoptó, debe seguir utilizándose para la descripción de la naturaleza, podemos dar el nombre de arqueología de la naturaleza, en contraste con el arte, a lo que el primero indica literalmente, a saber un relato del estado en tiempos pasados o antiguos de la tierra, un tema sobre el cual, aunque no nos atrevemos a esperar ninguna certeza, tenemos buenos motivos para conjeturar. Los restos fósiles serían objetos para la arqueología de la naturaleza, así como las piedras groseramente cortadas, y cosas de ese tipo, lo serían para la arqueología del

ignorancia no siempre me lo permitió (como en el caso del idioma alemán). La edición consultada puede chequearse en la bibliografía. 
arte"(Kant 2007: 257,cursivas mías)

Así, Kant primero piensa en una arqueología como opuesta a la historia (recuérdese que se hablaba de "historia natural") en tanto se ocupa de lo primigenio o verdaderamente antiguo. Luego atribuye los fósiles a la "arqueología de la naturaleza" (hoy hablaríamos de paleontología o paleobiología), y los artefactos líticos, a la "arqueología del arte"; esto es, la arqueología actual. Estas definiciones invitan a pensar que Kant usa el término "arqueología"ateniéndose a la etimología de la palabra, dado que opone una arqueología del arte a una arqueología de la naturaleza, lo que daría cuenta de una inestabilidad en la designación como arqueología de la disciplina (caso contrario Kant no hubiera adjetivado el término).

En un apunte de 1791 titulado Qué progreso real ha logrado la Metafísica en Alemania desde los tiempos de Leibniz y Wolff plantea:

"(...) una historia filosófica de la filosofía es en sí misma posible, no histórica o empíricamente, sino racionalmente, es decir, a priori. Porque aunque establece hechos de la razón, no los toma prestados de la narrativa histórica, sino que los extrae de la naturaleza de la razón humana, como arqueología filosófica." (Kant 1791 citado por McQuillan 2010:41)

Aquí entonces se perfila ya un cambio. La arqueología filosófica estudia las ideas precedentes en tanto razonamientos, sin entrar en sus circunstancias históricas o biográficas.

Cuando Kant escribe esto,la disciplina arqueológica aún estaba en formación. Si bien hay autores que consideran que Kant usa la palabra "arqueología"para aludir expresamente al carácter de la excavación arqueológica (Malinconico 2012), hay que recordar que las primeras excavaciones se habrían realizado apenasu nos 50 años antes de la escritura de estos textos y éstas aun no tenían el carácter que iban a tener durante el siglo XIX. Por ello es difícil que Kant haya podido vincular el concepto de excavación estratigráfica-una novedad en desarrollo-, con el de arqueología filosófica, aunque es evidente que por lo menos conocía la asociación entre artefactos líticos y la arqueología (ver arriba). La excavación arqueológica como tropo surge recién a finales del siglo XIX.

\section{Freud y la metáfora de la excavación arqueológica}

En su trabajo de 1894 sobre la histeria dice Freud:

"Supongan que un investigador viajero llega a una comarca poco conocida, donde despierta su interés un yacimiento arqueológico en el que hay unas paredes derruidas, unos restos de columnas y de tablillas con unos signos de escritura borrados e ilegibles. Puede limitarse a contemplar lo exhumado e inquirir luego a los moradores de las cercanías, gentes acaso semibárbaras, sobre lo que su tradición les dice acerca de la historia y el significado de esos restos de monumentos; anotaría entonces los informes ... y seguiría viaje.Pero puede seguir otro procedimiento; acaso llevó consigo palas, picos y azadas, y entonces contratará a los lugareños para que trabajen con esos instrumentos, abordará con ellos el yacimiento, removerá el cascajo y por los restos visibles descubrirá lo enterrado". (Freud2013:192)

Contemporáneo de la época de las grandes excavaciones del siglo XIX, Freud fue además arqueólogo amateur y coleccionista de antigüedades clásicas (Gay 1988). Así que, en este caso, el uso de la palabra arqueología, y más precisamente de la excavación arqueológica como metáfora, es transparente. Por otro lado, deja en claro lo que Freud consideraba era el trabajo arqueológico:

1) la arqueología transcurre en lugares exóticos("comarca poco conocida")

2) la arqueología es de época clásica ("paredes", "columnas", "tablillas")

3) los locales son (semi) bárbaros y tienen tradiciones sobre esas cosas pero...

4) es mejor excavar ("puede seguir otro procedimiento...") y no creerles, esto es, hacer arqueología y no etnografía

5) eso sí, los nativos son buena mano de obra barata ("y entonces contratará a los lugareños para que trabajen con esos instrumentos...")

6) hay cosas para descubrir que están enterradas ("por los restos visibles descubrirá lo enterrado").

Varios años más tarde, Freud explica el psicoanálisis de esta manera:

"El trabajo de construcción [del psicoanalista], o, si se prefiere, de reconstrucción, se parece, en gran medida, a la excavación que hace un arqueólogo de una vivienda que ha sido destruida y enterrada o de algún edificio antiguo. De hecho, los dos procesos son idénticos, excepto que el analista trabaja en mejores condiciones y tiene más material a su disposición para ayudarlo, ya que no está tratando con algo destruido sino con algo que aún está vivo. Pero así como el arqueólogo construye las paredes del edificio a partir de los cimientos que han permanecido en pie, determina el número y la posición de las columnas a partir de las depresiones en el piso y reconstruye las decoraciones murales y las pinturas a partir de los restos encontrados entre los escombros, también así procede el analista cuando extrae sus inferencias a partir de los fragmentos de recuerdos, de las asociaciones y del comportamiento del sujeto del análisis". (Freud 1964: 257)

Freud considera que detrás de lo dicho hay un discurso 
"enterrado" que se puede rescatar y conocer. En la terapia, el descubrimiento de las escenas se hace en una secuencia cronológica invertida, lo que justifica su comparación con la excavación de un yacimiento arqueológico o más precisamente, un yacimiento arqueológico de la época clásica:

"(...) Se entiende a la conciencia como estando en la superficie, y el inconsciente como estando "debajo" o "adentro", mientras que la represión restringe el movimiento ascendente de pensamientos e imágenes. Esto ya sugiere estratificación pero Freud enfatiza el elemento arqueológico al considerar que la represión no solo mantiene el material en su lugar, sino que también lo conserva, como un depósito arqueológico" (Thomas 2009:52-53)

Así, como argumenta Thomas (2009), Freud no solo tomó la imagen que la arqueología se hizo de sí misma sino que también ayudó a elaborarla:

"(...) esta forma particular en la que Freud movilizó la imagen del pasado antiguo, aprovechó e informó la percepción de la arqueología a principios del siglo XX, como una forma de investigación capaz de ir más allá de los aspectos transitorios de la existencia contemporánea, y abordando algo de la esencia humana duradera. (...) El trabajo de Freud ha contribuido a una concepción esencialista de la arqueología como una disciplina que indaga en las profundidades del pasado en busca de las verdades ocultas y originales de la condición humana" (Thomas 2009:58-60).

Entonces, a partir de Freud, la metáfora de buscar lo no dicho -que debe ser visibilizado o"excavado"- a partir de las huellas o restos que quedan visibles o en la superficie,más que un tropo se convierte en un auténtico meme que puede ser rastreado en otras disciplinas como la historia, las ciencias de la educación o la antropología histórica (ver Le Roy Ladurie 1975, Julien 2000, Artieda 2015 entre otros).

Si bien el uso metafórico de Freud, no se relaciona con el etimológico que planteaba Kant, veremos que ambos usos comienzan lentamente a hibridarse.

\section{De la Fenomenología a Benjamin}

Edmund Husserl también utilizó el término "arqueología", pero entretejiendo la concepción de Freud con la fenomenología. Husserl define la arqueología fenomenológica como "excavar (...) los edificios constitutivos ocultos en los elementos construidos, las construcciones de las operaciones de los sentidos aperceptivos que completan nuestra edificación como mundo de experiencia" (citado en Paltrinieri 2015:21). Husserl fue el primero en reconocer la disputa por el nombre, ya que, según señaló Fink,"(...) siempre lamentó que la expresión que realmente captura la esencia de la filosofía ya haya sido tomada por una ciencia positiva, esto es, la expresión 'arqueología' " (Fink 1939:246).
Puede considerarse a la empresa fenomenológica como un regreso a "las arqui-evidencias disimuladas que fundan las evidencias del sentido común" (Paltrinieri 2015:22) detectando las capas pre-teóricas o primitivas que son constitutivas de la percepción corporal, haciendo así posible la experiencia, pero al mismo tiempo siendo irreductible a esta (Paltrineri 2015).Su discípulo, Merleau-Ponty considerará a su fenomenología como arqueológica, para acentuar la importancia del origen (Triggs 2014, Paltrinieri 2015), diferenciándose de la metáfora freudiana en tanto la estructura arqueológica está implicada en la percepción misma y en el cuerpo humano (Triggs 2014 ).

Lévi-Strauss también usa este término en su"Introducción" a la obra de Marcel Mauss: al hablar de las técnicas corporales plantea que la creación de archivos internacionales de técnicas corporales permitirá plantear "una arqueología de hábitos corporales que, en la Europa moderna (y aún más en otros lugares), proporcionaría al historiador de las culturas un conocimiento tan valioso como la prehistoria o la filología" (Lévi Strauss 1950: XIV, cursivas mías). Si bien no es del todo claro por qué usa este término, posiblemente esté relacionado con su uso fenomenológico.

Walter Benjamin, en cambio, sigue el uso freudiano. En "Excavation and Memory" un corto texto que se publicó postmortem, escribe:

"El lenguaje ha dejado inequívocamente claro que la memoria no es un instrumento para explorar el pasado, sino un medio. Es el medio de lo que es experimentado, así como la tierra es el medio en el que las ciudades antiguas yacen enterradas. Aquel que busque acercarse a su propio pasado enterrado debe comportarse como un hombre cavando. Sobre todo, no debe tener miedo de volver una y otra vez al mismo asunto; esparcirlo como se esparce la tierra, darlo vuelta como se da vuelta el humus. Porque el "asunto en sí", no es más que los estratos que brindan sus secretos más buscados, solo ante la investigación más meticulosa. Es decir, contienen esas imágenes que, separadas de todas las asociaciones anteriores, residen como tesoros en las sobrias habitaciones de nuestras ideas, como torsos en la galería del coleccionista. Es sin duda útil planear excavaciones metódicamente. Sin embargo, no menos indispensable es el sondeo cauteloso de la pala en el suelo. Y el hombre que simplemente hace un inventario de sus hallazgos, mientras no pueda establecer la ubicación exacta de dónde se han almacenado los antiguos tesoros en el terreno del hoy, se engaña en la obtención de su premio. En este sentido, es mucho menos importante que el investigador informe sobre auténticos recuerdos que marcar, con bastante precisión, el sitio en donde se los apropió. Épica y rapsódica en el sentido más estricto, la memoria genuina debe brindar una imagen de la persona que recuerda, de la misma forma en que un buen informe arqueológico no solo nos informa sobre los estratos en 
los que se encuentran los hallazgos, sino que también da cuenta de los estratos que tuvieron que atravesarse para llegar a aquel" (Benjamin 1999b: 576).

Si bien Benjamin se refiere en este párrafo a la arqueología clásica (véase "torsos en la galería del coleccionista","tesoros" y la alusión al "informe arqueológico") el término "arqueología"no es mencionado explícitamente. Lo mismo ocurre en el resto de su obra: desde sus reflexiones sobre el coleccionismo hasta el Arcades Project (Benjamin 1999a) tiene una mirada arqueológica, vinculada a la arqueología actual antes que a la que se practicaba en la época en que escribía esos textos (Olivier 2008). Criticando el historicismo y la percepción del pasado como un continuum, Benjamin considera que el pasado es una composición de imágenes. “Estas imágenes no son universales ni constantes; aparecen, cambian y se transforman en relación con las preocupaciones contemporáneas. Con el tiempo se transforman en 'el pasado' a través de un esfuerzo continuamente renovado"(Russell 2013: 297). Para Benjamin, el pasado no es algo acabado sino que es el presente mismo.

\section{Foucault y La arqueología del saber}

Para Foucault proceder arqueológicamente significa buscar el conocimiento implícito que hace posible la emergencia de teorías, opiniones y prácticas dentro de una determinada sociedad en un momento determinado (Malinconico 2012). En una entrevista realizada en 1972, Foucault se refiere a una reseña de su libro Las palabras y las cosas publicada por George Steiner en la prestigiosa New York Times Book Review. Como Steiner consideró allí que la denominación "arqueología de las ciencias humanas" (el subtítulo de Las palabras y las cosas) se debía al aura de profundidad de que gozaba el término, al menos desde Freud, Foucault contraataca: "El comentarista [Steiner] no sabe (...) que Kant usó esta palabra para designar la historia de aquello que hace necesaria una cierta forma de pensamiento (...)"(citado por McQuillan 2010:39).

Entonces, a partir de esta respuesta podría decirse que Foucault usa el término en un sentido kantiano, siendo además un especialista en este filósofo. Sin embargo, no es tan sencillo. Foucault lo usa por primera vez en su primer trabajo, publicado en 1954,Maladie mentale et personnalité. Allí "arqueología" refiere a

"(...) 'etapas arcaicas' a través de las cuales, de acuerdo con el psicoanálisis, evolucionó el individuo (...). Esto sugiere un sentido psicológico de 'arqueología', que apenas se relaciona con el significado que Foucault le dio al término en sus siguientes trabajos."(Árnason2018:8).

El mismo Foucault admite que al principio usó el término de manera "algo ciega" (citado en Árnason 2018:8). Foucault vuelve a usar este término en El nacimiento de la Clínica como subtítulo ("una arqueología de la mirada médica") y finalmente en Las palabras y las cosas(como se dijo, subtitulada "una arqueología de las ciencias humanas") para designar a lo que hace el conocimiento posible es decir "(...) reglas o principios dentro del sistema de pensamiento, que organizan y estructuran el campo del conocimiento dentro de una disciplina en un período determinado (y, por lo tanto, son históricos)" (Árnason 2018:9)

Pero, según Foucault (2002) mientras la historia de las ideas trata al discurso como un documento -signo de alguna otra cosa- la arqueología describe al discurso como un monumento que debe analizarse por sí mismo, intrínsecamente, y no como alegoría de ninguna otra cosa:

"Hubo un tiempo en que la arqueología, como disciplina de los monumentos mudos, de los rastros inertes, de los objetos sin contexto y de las cosas dejadas por el pasado, tendía a la historia y no adquiría sentido sino por la restitución de un discurso histórico; podria decirse, jugando un poco con las palabras que, en nuestros días, la historia tiende a la arqueología, a la descripción intrínseca del monumento".(Foucault 2002:11).

Entonces, si bien Foucault reconoce el origen de su uso del término en Kant, no por ello reniega de las posibilidades de la "metáfora de la excavación arqueológica". Y nuevamente, considera como arqueología a la clásica del siglo XIX ("monumentos", "objetos sin contexto", "adquiría sentido solo a través de la restitución de un discurso histórico"). De alguna forma, comienza entonces a hibridarlos, volviendo al tropo de la excavación por más que explícitamente lo rechazara: "(...) me molesta la idea de la excavación (...). Al contrario intento definir relaciones que están en la superficie misma de los discursos; Intento volver visible lo que es invisible solo por estar en la superficie de las cosas"(citado por Paltrinieri 2015:26). Pero, Malinconico considera una mayor vinculación con ese tropo que que la Foucault admitiría:

"Cuando un arqueólogo saca a la luz una columna dórica, un traje funerario, una sentencia de la corte, está obligado a presentar todas las pruebas por igual; esto es como 'hechos históricos', y los cataloga sin establecer una jerarquía real. Cada hallazgo contribuye, en su especificidad, para iluminar algo que parecía estar perdido. Para dar una idea del complejo mundo afectivo, religioso y cultural que gravitaba en torno a esos objetos, será necesaria una tarea diferente. Se requiere un procedimiento que reconstruya el pasado a partir del material dado para que podamos leer el tipo de adoración que se practicaba en esos templos, o los valores que vinculan al difunto con cada uno de sus ornamentos, o incluso los conflictos que acompañaron la conformación de una regulación antes que otra. Este es el trabajo del historiador. Para el arqueólogo, sin embargo, lo que viene primero es la "positividad" de los mismos objetos, sus valores intrínsecos y su objetividad impasible" 
(Malinconico 2012:63-64).

Esta vinculación de la arqueología de Foucault con el tropo de la excavación también es reconocida por Podgorny (1999):

"La analogía entre la arqueología y la historia de las ideas es más que una metáfora ya que con ello se quiere afirmar la importancia de diferenciar agrupaciones y fragmentos que pertenezcan a un todo y no a otro desde el punto de vista de su procedencia en el tiempo y en su uso (...). Por otro lado, esta analogía señala la importancia de lo descartado y hace que todo se transforme en fuente en el sentido de una excavación arqueológica moderna donde -como todo manual de arqueología establece- interesan no solo los objetos sino a) la relación entre ellos, b)la relación entre ellos y el sustrato que los contiene y c) la relación de todo lo hallado con los procesos que llevaron a que el investigador que lo observa en el presente los observe en ese contexto" (Podgorny 1999:3-4)

De manera paradójica, hay que señalar que, justamente, cuando Foucault plantea su arqueología como método de investigación filosófica/histórica, focalizado en la descripción del "monumento" y en los "objetos sin contexto", la arqueología como disciplina, comienza a alejarse de éstos y, tal como lo expresa Podgorny arriba, comienza a centrarse en la relación entre ellos, con el sustrato que los contiene y con los procesos de formación. Para la denominada Nueva Arqueología o Procesualismo, contemporánea a Foucault,lo importante no son los objetos sino su contexto.

Más recientemente, en línea con el uso foucaultiano, Giorgio Agamben parte de los usos del término previos (Kant, Nietzsche, Ricœur y Melandri ) para considerar que cada pensador construye su trabajo sobre las ruinas de otro, por lo que "La arqueología, entonces, es una ciencia de ruinas, una 'ruinología'"(Agamben 2009:82) y que puede llamarse arqueología a "esa práctica que, en cualquier investigación histórica, no tiene que ver con los orígenes sino con el momento del surgimiento de un fenómeno $\mathrm{y}$, por lo tanto, debe generar un nuevo compromiso con las fuentes y la tradición"(Agamben 2009:89 cursivas mías). También, en el ámbito de la Historia del Arte $^{3}$, Didi-Huberman (2008), desde una óptica benjaminiana y sosteniendo la existencia de un anacronismo fundamental en el arte, vuelve a usar el término.

Finalmente, dentro de este mismo "linaje", hay que mencionar la corriente que se define como "Archaeology of Media" o "Media archaeology" un enfoque que encara el estudio de los medios a partir de las ideas de Foucault, Benjamin y Friedrich Kittler. Para este enfoque:

"Los rastros perdidos de las tecnologías de los medios

\footnotetext{
3 Previamente hay que mencionar también los trabajos de Aby Warburg y su idea de una historia del arte "arqueológica" que no requiere textos, solo imágenes.
}

se consideran temas importantes para ser excavados y estudiados; Las tecnologías mediáticas "muertas" y los desarrollos idiosincrásicos revelan temas, estructuras y vínculos importantes en la historia de la comunicación que usualmente son cubiertos por narraciones más obvias. Esto incluye el rastreo de desarrollos irregulares y genealogías no convencionales de las tecnologías de la comunicación actuales, en la creencia de que los desarrollos más interesantes a menudo ocurren en los márgenes descuidados de las historias o de los artefactos." (Parikka y Hertz 2010)

Al mismo tiempo, los investigadores enrolados dentro de esta disciplina (entre quienes pueden mencionarse Siegfried Zielinski, Wolfgang Ernst, Thomas Elsaesser, y Erkki Huhtamo) quieren diferenciarse de la arqueología como disciplina:

"La arqueología de los medios no debe confundirse con la arqueología como disciplina. (...) La arqueología de los medios revuelve archivos textuales, visuales y auditivos, así como colecciones de artefactos, enfatizando las manifestaciones discursivas y materiales de la cultura. Sus exploraciones se mueven fluidamente entre disciplinas, aunque no tiene un hogar permanente dentro de ninguna de ellas." (Huhtamo y Parikka 2011:3)

Hasta aquí entonces lo que podríamos llamar el "linaje" filosófico.Nos resta revisar otro "linaje", ya no estrictamente del término "arqueología" sino centrado en el concepto de "arqueologización" .Esto implica un cambio de escala espacial (ya que este concepto tiene un impacto americano, y particularmente argentino) y temporal (ya que abarca solo las últimas tres décadas). Me refiero a lo que llamare el "linaje" poscolonial.

\section{El linaje poscolonial}

Mary Louise Pratt generó una cierta cantidad de conceptos (zona de contacto, autoetnografía y anticonquista entre aquellos que tuvieron más difusión, ver Lindsay 2011) para analizar la literatura de viajeros (Pratt 1992) y éstos fueron luego aprovechados y difundidos en diferentes ámbitos académicos. Si bien muchos de los conceptos acuñados por Pratt recibieron criticas ulteriores (centradas en la sobresimplificación de la visión de los viajeros y una subestimación de la complejidad de los procesos de la negociación de identidades ver Lindsay 2011), el menos conocido concepto de arqueologización, ${ }^{4}$ que Pratt (2011) utiliza para analizar la obra de Humboldt, no fue objeto de críticas específicas. En lo que sigue revisaré los usos que tuvo este concepto en Argentina, uno de los países donde tomó más fuerza, aunque también tuvo impacto en la literatura anglosajona (ver Florescano 1994, Sluyter 2006, Bruchac 2010, Park, 2014 entre otros).

\footnotetext{
4 Con anterioridad a Pratt, Lukács (1962) utiliza "arqueologismo" pero para referirse al comportamiento de ciertos autores de novelas históricas, como Flaubert, cuando describen los objetos del pasado con "precisión profesional".
} 
En un parágrafo titulado "América arqueologizada" Pratt (2011) sostiene que:

"... los vínculos entre las sociedades arqueologizadas y sus descendientes contemporáneos permanecen absolutamente oscuros, de hecho irrecuperables (...) La imaginación europea produce sujetos arqueológicos escindiendo a los pueblos contemporáneos no europeos de sus pasados precoloniales, y hasta coloniales. Revivir la historia y la cultura indígenas como arqueología es revivirlas muertas. Al hacerlo, al mismo tiempo que se les rescata del olvido europeo, se les reasigna a una era que ya fue. (...) Lo que los colonizadores matan como arqueología suele vivir entre los colonizados como autoconocimiento y conciencia histórica(...)"(Pratt 2011:251-252)

Como vemos, la definición de Pratt (1992) considera que arqueologizar es revivir lo muerto, generar algo así como un zombie cultural. Esta definición permite suponer, además, una división del trabajo intelectual, según la cual mientras la arqueología se ocupa de lo muerto, la etnografía/antropología se ocupa de lo vivo. Este nuevo tropo impactará en diversos ámbitos académicos a partir de entonces, aunque mucho más restringido espacialmente que el caso anterior.

El primero en recuperar este término en Argentina fue el antropólogo Hernán Vidal (1993) en su tesis de maestría. Allí trasladó la arqueologización ${ }^{6}$ a la praxis arqueológica que le era contemporánea y al ámbito de Tierra del Fuego:

"Ese proceso de arqueologización de los indios fueguinos, (...), junto al distanciamiento crítico de los arqueólogos de los años 80 respecto al uso indiscriminado de la proyección etnográfica (...) hacía posible apropiarse y manipular las imágenes etnográficas heredadas con un amplio margen de libertad intelectual" (Vidal 1993: 30).

Así, considera que la cultura indígena era resultado de un "proceso (...) ubicado temporal y conceptualmente en el pasado regional. Un pasado remoto, prehistórico, marcadamente discontinuo respecto al presente. (...)" (Vidal 1993:61). Y concluye: "Los arqueólogos instalamos definitivamente a los indios fueguinos en el pasado (...)los reubicamos en un pasado de características propias: la prehistoria (Vidal 1993:61)".

Por ello, para Vidal, el mecanismo que instala a los indígenas fueguinos en el pasado es arqueológico. De manera casi contemporánea a los planteos de Vidal (ver también Scheinsohn y Bellelli 2018), pero por fuera del ámbito antropológico, Quijada (1998) alude a un concepto semejante, aunque no usa el término arqueologización. Al hablar del Perito Moreno sostiene que

\footnotetext{
${ }^{5}$ Esta tesis fue recientemente publicada en Rodríguez et al. (2018)

${ }^{6}$ Al referirse a este concepto, Vidal no cita específicamente a Pratt (2011), pero este libro figura en la bibliografía de su tesis.
}

“(...) su actuación como antropólogo, (...) combinó el estudio del indígena prehistórico con el del indígena contemporáneo, y su articulación en el proceso argentino de construcción nacional. En este contexto se desarrolla (...) la aplicación simultánea a unos mismos individuos de las categorías de ancestros, ciudadanos y piezas de museo"(Quijada 1998: 1).

Si bien hay una serie de trabajos que citan a Quijada (1996, 1998 , 1999) como fuente del término arqueologización ${ }^{7}$ no pude encontrar el uso explícito de ese término (aunque el concepto está allí, ver la cita previa). El término aparece también en un artículo de 1998, referido a Alfred Metráux, de la antropóloga Patricia Arenas. Lo usa en un sentido similar al de Pratt (2011) incluso haciendo explícita la división intelectual del trabajo entre la arqueología y la etnografía, pero no cita a esa autora:

"La práctica de Arqueología se destinaba a 'resucitar la civilización de las regiones en que las poblaciones primitivas van desapareciendo', las comunidades etnográficas se encontraban en proceso de arqueologización y la Etnografía moderna era un complemento de la Arqueología en la estrategia de conocimiento de aquellas" (Arenas 1998:125 cursivas mías)

Un poco más tarde, Anderman (2000), enmarcado en la crítica cultural, considera que Francisco Pascasio Moreno propone una imagen de la Patagonia como"la de un inmenso sitio arqueológico, un mundo de restos inmóviles de 'remotas prehistorias'" (Anderman 2000:124). Y si bien no usa el término arqueologización, habla de la "paleontologizacion del otro" (Andermann 2000: 125) para sostener el "alejamiento en el tiempo" del indígena que propone Moreno.

Finalmente hay que destacar el caso de Navarro Floria (2006) quien habla de la "arqueologización conceptual" de la población indígena, lo que retoma en un trabajo posterior: "Una de las estrategias discursivas características del período posconquista en relación con el Otro fue su desplazamiento al pasado remoto y su arqueologización conceptual."(Azar et al. 2007:79 cursivas mías). Tampoco en este caso es claro si este concepto es una elaboración propia o lo toma de otros autores ${ }^{8}$. Posteriormente otros autores remiten a Navarro Floria (2007), a Azar et al. (2007) o Menard (2008) ${ }^{9}$

\footnotetext{
${ }^{7}$ Mientras que Teobaldo y Nicoletti (2007) cita a Quijada (1998 y 999), García y Miralles (2008) cita a Quijada (1996 y 1998)

${ }^{8}$ Vale como pista que el libro de Pratt aparece citado por Navarro Floria en otro capítulo (Salgado, Navarro Floria y Garrido 2007) del mismo libro en donde se encuentra el de Azar et al.2007

${ }^{9}$ Nagy (2012) utiliza este concepto y cita a Navarro Floria (2007) como origen. Kerr (2009), a su turno, lo toma de Azar et al.2007, mientras que Vezub (2009) en la nota 38 cita para el concepto de "literatura de la extinción y arqueologizacion de lo indígena" a Menard (2008), en donde "arqueologización" se registra en el siguiente contexto "(...) es interesante notar que el momento ideográfico, en toda su arqueologización del sujeto indígena en tanto sujeto extinto, puede
} 
Finalmente las antropólogas Rodríguez (2010) y San Martín (2013) lo toman de Vidal (1993). San Martin (2013) lo hace analizando el trabajo de Roberto J. Payró, contemporáneo de la arqueología de fines del siglo XIX, pero Rodríguez, como Vidal, lo lleva a lo contemporáneo.

Todo este panorama parece indicar que, con posterioridad a los planteos de Pratt (2011), hay un cierto conjunto de autores que, desde una perspectiva poscolonial, utilizan el término "arqueologización", presuponiendo que todos saben de lo que se habla y, en muchos casos, sin indicar si se lo ha tomado de un autor precedente o es una elaboración propia. Y a esto se suma que bajo la misma definición otros hablan de paleontologización, como intercambiable con el de "arqueologización". Si bien puede trazarse un linaje que va de Pratt a Vidal y de ahí a Rodríguez y San Martin, con los otros autores resulta más complejo restituir el origen del uso. ${ }^{10}$ En definitiva todos estos autores coinciden en que en la literatura, la historia y la antropología argentina, existe una operación de "remotizar" a los indígenas, y muchos de ellos coinciden en llamar a esa operación "arqueologización".

\section{Discusión}

Este recorrido permitió identificar dos "linajes"en el uso del término "arqueología", por fuera de la disciplina del mismo nombre: el "linaje" filosófico, en el cual se parte de una consideración etimológica que luego termina por hibridizarse con un tropo de la excavación arqueológica, basada en la arqueología clásica del siglo XIX,y un "linaje" poscolonial que, con un uso más restringido, también se fundamenta en la arqueología clásica del siglo XIX y en el tropo de la división intelectual del trabajo entre la arqueología (como estudio de lo muerto) y la etnografia (como estudio de lo vivo) y en el papel que cumplió la arqueología en la invisibilización del indígena durante el siglo XIX.

En el primer caso, el término arqueología empieza siendo disputado entre la filosofía y la naciente disciplina entre los siglos XVII y XVIII. Cuando se establece la arqueología con ese nombre, la filosofía no resigna ese término. El posterior uso del término "arqueología", en el siglo XIX, tiene un correlato con la arqueología que le es contemporánea. Pero con el correr de los años ese uso queda cristalizado mientras que la disciplina continúa su desarrollo.

La metáfora tiene un papel clave como mecanismo

ser entendido como el posicionamiento de la mismidad científica ante la figura de una escritura sin palabra (o al menos sin una palabra propia)" (Menard 2008:264)

10 Quijada $(1996,1998,1999)$ es citada por varios pero allí, como se dijo, si bien está planteado el concepto, no figura ese término en especial. Navarro Floria (2006, Azar et al 2007) es otro de los más citados pero arqueologización se presenta con una definición más implícita que explícita. Asimismo ni Vidal, ni Anderman señalan el origen de los términos que utilizan (arqueologizacion y paleontologizacion respectivamente) aunque ambos citan a Pratt (1992) en sus trabajos. cognitivo en general (ver por ejemplo Sontag 1978 o White 1973) y en particular en el ámbito científico (Lakoff y Johnson 1980, Kuhn 1979, 1990, Agustì 1987, Bachelard 1985 entre otros).Si nos centramos en cómo fue utilizada la arqueología como metáfora es claro que, en términos públicos y mediáticos, está atada a una representación de la arqueología clásica del siglo XIX, ligada al coleccionismo, en la cual los objetos están escindidos de su función originaria, donde se buscan tesoros, la aventura y el esfuerzo individual siendo su mejor símbolo la figura de Indiana Jones (hombre, blanco, heterosexual ver Salerno y Pupio 2009). Esa metáfora genera prejuicio y perjuicio: impide comprender lo que la arqueología del siglo XX y XXI tiene para ofrecer.La "popularización" del término arqueología en manos de Foucault, llevó finalmente a un malentendido: su "arqueología"no tiene que ver con la disciplina arqueológica que le era contemporánea. Así, quienes esperen de la arqueología de fines del siglo $X X$ y principios del XXI objetos, monumentos y ruinas, se verán decepcionados. Entre los cambios más importantes pueden contarse:

1) la arqueología actual ha abandonado el pasado como territorio exclusivo. El mismo procesualismo, consideraba que "la arqueología no era exclusivamente prehistórica ni estaba necesariamente comprometida con el pasado remoto, sino que también estaba relacionada con cualquier momento histórico, incluido el presente" (Scheinsohn y Fondebrider 2015). Posiblemente el punto de inflexión de esta idea haya surgido con el Garbage Project desarrollado en Tucson (EEUU) en los años setenta (Rajthe y Murphy 1992). Las investigaciones arqueológicas de lo contemporáneo apuntan a que la materialidad y su contexto tienen algo que aportar, que no fue dicho documentalmente, y que tienen efectos en ese presente:

"Este es un tropo que, creo, vale la pena preservar: la capacidad de la arqueología para ver cosas que parecen invisibles incluso aunque estén frente a nuestros ojos" (González Ruibal 2013: 22)

Si no puede sostenerse la dicotomía pasado-presente tampoco es dable sostener la división del trabajo intelectual entre la arqueología dedicada al pasado y la etnografía/antropología al presente. Así, la arqueología puede plantearse un nuevo papel que consistirá en no solo

"documentar pasados remotos que se han ido para siempre, sino también documentar la prehistoricidad de nuestro presente. Esta prehistoricidad no debe entenderse como atavismo o supervivencia (...), sino como una tendencia presente y operativa (una arché) que condiciona y hace inteligible el presente mismo (Agamben 2009: 92)"(González Ruibal 2013:12).

Olivier (2019) plantea incluso una arqueología benjaminiana partiendo de que la "historia materialista" de Benjamin es básicamente una "arqueología del 
presente" o sea un enfoque del pasado "dentro del presente" enfatizando la importancia de su supervivencia.

Si bien Olivier plantea esta idea del pasado desde un marco teórico explícitamente benjaminiano, esta no es ajena a varios de los autores que se enrolan en lo que se conoce como posprocesualismo, pero tampoco al procesualimo. En 1981 Binford afirmó que el registro arqueológico era un "fenómeno estático contemporáneo" (Binford 1981: 25). Y en un trabajo posterior se explaya:

"El registro arqueológico está aquí, con nosotros, en el presente. Está allá, enterrado, con muchas posibilidades de ser descubierto al construirse una nueva carretera; es una parte importante de nuestro mundo contemporáneo y las observaciones que hacemos sobre él están aquí y ahora, son nuestras, contemporáneas. No son observaciones directas que sobreviven del pasado (...). Los hechos observados del registro arqueológico son actuales y por sí mismos no nos informan acerca del pasado". (Binford 1991:23).

Esta frase podría haber sido subscripta por Benjamin, pero es difícil pensar que Binford haya frecuentado a Benjamin. Para fortalecer esta similaridad de enfoque solo me resta destacar la coincidencia de que, para repensar los múltiples tiempos coexistiendo en sincronía, tanto Binford (1981:197) como Olivier (2012: 11), se valieron de la metáfora del palimpsesto.

2) También, excavación ya no es igual a arqueología. Si bien sigue siendo uno de los métodos de base, hay muchas otras formas de "hacer" arqueología que incluyen el estudio de distribuciones de materiales en superficie, el trabajo con comunidades locales, trabajos experimentales, simulaciones, etc.

3) Varios trabajos realizados desde una perspectiva poscolonial (ver por ejemplo Lydon y Rizvi 2010) se encargaron de comenzar a librar a la arqueología de sus contenidos colonialistas. Esto no quiere decir que toda arqueología sea poscolonial, pero sí que la mayoría de los practicantes de la arqueología hoy son conscientes del sesgo colonialista de la disciplina.

En cuanto al linaje poscolonial, si bien las operaciones destinadas a invisibilizar a los pueblos originarios son innegables, que esa operación se denomine arqueologización revela que en Argentina, para las ciencias sociales y las humanidades la arqueología viene a ser una ciencia positivista que, a partir de la separación ontológica entre pasado y presente, se dedica a estudiar el pasado (que, en tanto, tal está muerto), correspondiéndole el presente a la antropología. Esta imagen de la arqueología es especialmente evidente en los textos antropológicos, lo cual es paradójico si se tienen en cuenta la cercanía académica de estas disciplinas, que comparten el mismo departamento en muchas universidades del país. Si bien la comunidad arqueológica tuvo responsabilidad en esa construcción (y este análisis merecería un artículo en sí mismo) es cierto que una vez que esta imagen fue adoptada por la antropología, una serie de factores locales llevaron a su cristalización y a una posterior incomunicación entre estas disciplinas. Por un lado, la llegada del procesualismo a la Argentina en la década del ochenta llevó a plantear pretensiones cientificistas que la alejaron de la antropología. Por el otro, la competencia por puestos de trabajos y subsidios entre estas disciplinas se endureció de tal forma que las barreras establecidas comenzaron a hacerse irremontables ${ }^{11}$. Lo cierto es que la propia arqueología argentina ha cambiado respecto de esa imagen. Tanto la conformación del Equipo Argentino de Antropología Forense en 1984 (Fondebrider y Scheinsohn 2015) como la crítica postprocesual de los noventa (Zarankin y Acuto 1999), entre otros posibles ejemplos, señalan una reivindicación de la contemporaneidad como territorio arqueológico.

\section{Conclusiones}

Lo que he intentado hacer en este artículo es delinear la historia de una gigantesca confusión con la idea de que quienes practicamos la arqueología sepamos cómo fue que llegamos hasta aquí y cómo fue que el término arqueología se hizo importante en el desarrollo de la filosofía occidental, importancia que, entiendo, muchos colegas no tienen presente. Por otro lado, este trabajo también intenta presenta una nueva versión de la arqueología a la otras disciplinas. Es en este sentido que planteo este trabajo como una guía para abordar las relaciones con las demás disciplinas, partiendo de una arqueología de límites porosos. En Argentina, los primeros pasos de la arqueología apuntaron a la invención de un pasado poblado de bestias asombrosas y ruinas de civilizaciones extintas,mientras que los indígenas de aquel presente fueron convenientemente invisibilizados (Scheinsohn y Fondebrider 2015). En el transcurso de esa historia en donde la arqueología y otras disciplinas comenzaron coexistiendo bajo el paraguas de la historia natural, surgieron barreras disciplinares que llevaron a la conformación de la arqueología local como disciplina "mestiza", con un pie en las ciencias naturales y otro en las humanidades y las ciencias sociales. González Ruibal (2013)considera que ha llegado el momento de reclamar el uso del término arqueología con la diversidad, variedad y compromiso que tiene en la actualidad. Sin embargo, entiendo que este reclamo se hace sobre un territorio cenagoso. ¿O es que todos quienes practicamos la arqueología estaríamos de acuerdo en reivindicarla como la disciplina del origen, como lo plantea la etimología del término y el tropo de Freud? De hecho, la capacidad de visualizar lo invisible por superficial

\footnotetext{
11 Valga como ejemplo de institucionalización de esta situación el caso de la Comisión Asesora de Historia, Geografía y Antropología del CONICET que albergaba a ambas y que en el 2017 fueron separadas de Historia y Geografía en dos comisiones: la de Antropología y la de Arqueología y Antropología biológica.
} 
(Foucault o González Ruibal ver arriba) sería algo más acorde a la situación actual de la arqueología. Es más, podríamos preguntarnos si el término arqueología, dada su etimología y su historia, refleja lo que hacemos hoy. En momentos en que lo que nos une a sus practicantes es poco más que una metodología (otra vez, el poderoso tropo de la excavación) cabe también cuestionarse si poder compartir el nombre de la disciplina nos permitiría una nueva forma de construir conocimiento, una forma para la que los compartimientos estancos disciplinares son obstáculos epistemológicos antes que necesidades. La fluidez de nuestro territorio,que conocemos por nuestra tradición mestiza, nos deja en una situación más que apropiada para dialogar con las demás disciplinas. Pero para ello sería necesario confrontar los estereotipos que se nos atribuyen. Así como Podgorny(1999) lo registró en los textos escolares, y Salerno y Pupio (2009) en los textos periodísticos, podemos decir que también en el terreno académico la percepción de la arqueología atrasa. Y convengamos que es difícil establecer un diálogo con la antropología si todavía piensa en nosotros como una disciplina de lo muerto, de lo extinto. Podemos y debemos dar debate sobre la materialidad del presente pero no estaremos autorizados a hacerlo mientras la antropología nos "arqueologice". Además, esa arqueologización tiene efectos concretos en el hoy. Por ejemplo, en una depreciación de la labor arqueológica y en una mala prensa en el ámbito de las humanidades que redunda en menos puestos de trabajo en las universidades o menos subsidios para la investigación. Esta es la tarea que tenemos por delante. Corresponde hacernos cargo de nuestras particularidades pero al mismo tiempo ser conscientes de la porosidad de nuestras paredes disciplinarias y la variabilidad interna de nuestras miradas, tanto en términos de nuestros marcos teóricos como también de nuestras identidades (políticas, de género, de religión, etc.). Mientras los estereotipos, pero también algunos colegas, nos presentan como un frente homogéneo, único y sin fisuras, volcado exclusivamente a pretensiones científicas, la historia trazada en las páginas precedentes permite reconocer heterogeneidades, fracturas y contradicciones.Nos toca ahora visibilizar y reconocer esa diversidad y a partir de allí confrontar los estereotipos para poder construir con las demás disciplinas, todas las que nuestro objeto de estudio requiera, un conocimiento más poroso.

Buenos Aires, 17 de marzo 2020, en el año de la peste.

\section{Agradecimientos}

En primer lugar a Cristina Bellelli con quien presenté una primera versión de este trabajo en el Primer Congreso de Historia de la Antropología Argentina en noviembre del 2018. A Marcela Croce por la cuidada y puntillosa lectura de un manuscrito previo y sus recomendaciones de lecturas. A Carlos López Beltrán por la lectura filosófica y a Jorge Fondebrider por ayudarme a hacer legible este trabajo.También a Leonor Acuña por su ayuda con las definiciones retóricas. Finalmente, a Garðar Árnason quien me envió por mail su muy apreciado capítulo sobre la arqueología de Foucault.

\section{Bibliografia}

Agamben, G.(2009). The signature of things. On method.New York:Zone Books.

Agustí, J.(1994).La evolución y sus metáforas. Barcelona:Tusquets.

Andermann, J. (2000). Mapas de poder. Una arqueología literaria del espacio argentino. Rosario: Beatriz Viterbo.

Arenas, P.(1998).Alfred Métraux: momentos de su paso por Argentina. Mundo de Antes1,121-147.

Árnason, G. (2018). Foucault's Archaeology of Knowledge. En: G. Árnason, Foucault and the Human Subject of Science(pp.7-30). Cham:Springer.

Artieda, T. (2015).Lecturas escolares, pueblos indígenas y relaciones interétnicas. Concepciones acerca de los indígenas en los libros de lectura de la escuela primaria argentina. Transformaciones y continuidades entre 1880 y 1940 circa. (Tesis Doctoral inédita) Universidad Nacional de Educación a Distancia, España.

Azar, P.,Nacach,G. y Navarro Floria, P. (2007).Antropología, genocidio y olvido en la representación del otro étnico a partir de la Conquista. En:Pedro Navarro Floria (comp.)Paisajes del progreso. La resignificación de la Patagonia Norte, 1880-1916. (pp. 79-106)Neuquén: Educo.

Bachelard, G. (1988). La formación del espíritu científico. México: Siglo XXI.

Benjamin, W. (1999a). The Arcades Project.Cambridge:Belknap Press of Harvard University Press.

Benjamin, W. (1999b).Selected Writings.Volume 2, Part 2 19311934. Cambridge: Belknap Press of Harvard University Press. M. Jennings, H.Eiland, y G. Smith(eds.).

Binford, L. (1981). Bones.Ancient Men and Modern Myths.New York: Academic Press.

Binford, L.(1991).En Busca del Pasado. Descifrando el Registro Arqueológico. Barcelona: Crítica.

Bruchac, M. (2010).Indigenous Journeys—Splinterville, Drenthe, Amherst.En: G.Nicholas (comp.) Being and Becoming Indigenous Archaeologists. (pp. 66-75) London y New York: Left Coast Press.

Buchli, V. y Lucas, G. (2001). The Absent Present: Archaeologies of the Contemporary Past. En: V. Buchli y Lucas, G. (comp.)Archaeologies of the Contemporary Past. (pp. 3-18) London: Routledge.

Daniel, G. E. (1967). The Origins and Growth of Archaeology. 
Harmondsworth:Penguins Books.

Didi-Huberman, G. (2008). La ressemblance par contact. Archéologie, anachronisme et modernité.Paris: Editions de Minuit.

Ebeling , K. (2016).The Art of Searching On "Wild Archaeologies" from Kant to Kittler. The Nordic Journal of Aesthetics 51, 7-18.

Ernst, W.(2011). Media Archaeography: Method and Machine versus History and Narrative of Media. En Erkki Huhtamo y Jussi Parikka (comp.)Media Archaeology. Approaches, Applications, and Implications, (pp. 239-255)Berkeley:University of California Press, 239-255.

Fink, E. (1939). Das Problem der Phänomenologie Edmund Husserls.Revue Internationale de Philosophie 2, 226-270.

Florescano, E. (1994). Memory, myth, and time in Mexico: From the Aztecs to independence.Austin: University of Texas Press.

Fondebrider, L. y V. Scheinsohn.(2015). Forensic Archaeology.The Argentinian Way.En: M. Groen, N. Marquez Grant y R. Janaway (comps.) Forensic Archaeology: A Global Perspective(pp. 369377). Londres: Wiley-Blackwell.

Foucault, M. (2002).La arqueologia del saber, Buenos Aires: Siglo XXI Editores Argentina.

Freud, S. (2013).La etiología de la histeria. En Obras completas Volumen 3 III. Primeras publicaciones psicoanalíticas (18931899), (pp. 185-218) Buenos Aires- Madrid :Amorrortu editores.

Freud, S.(1964). Constructions in Analysis.En: J. Strachey (ed.) The Standard Edition of the Complete Psychological Works of Sigmund Freud, vol. 23 (pp. 257-269)Londres:Hogarth Press.

García, A. y Miralles, G. (2006). Entre las áridas mesetas y la majestuosa belleza de los lagos: El sur argentino en los libros de lectura usados en escuelas rionegrinas. XIV Jornadas Argentinas de Historia de la Educación, La Plata, Argentina.http://www.memoria.fahce.unlp.edu. ar/trab_eventos/ev.13312/ev.13312.pd (Acceso 19 de diciembre 2019).

Gay, P. (1988).Freud: A Life for Our Time.Nueva York:Norton and Company.

González Ruibal, A. (2013). Reclaiming Archaeology.Beyond the Tropes of ModernityOxon: Routledge.

Haslam, H., Hernandez-Aguilar, A., Ling, V., Carvalho, S., de la Torre I.,DeStefano, A., Du Bruce Hardy,A., Harris,J., Marchant,L., Matsuzawa, T. ,McGrew,W.,Mercader, J., Mora, R.,Petraglia,M.,Roche,H., Visalberghi, E. y R. Warren,(2009). Primate archaeology. Nature, 460, 339-344.

Holtorf, C. (2005). From Stonehenge to Las Vegas: Archaeology as Popular Culture, Walnut Creek:Altamira.

Huhtamo E. y Parikka, J. (2011).Introduction. En: E. Huhtamo y J.
Parikka (comps.) Media Archaeology. Approaches, Applications, and Implications, (pp. 1-24) Berkeley :University of California Press.

Julien, C.(2000). Reading Inca History. Iowa City: University of lowa Press.

Kant, I. (2002). What real progress has metaphysics made in Germany since the time of Leibniz and Wolff ?.En:H. Allison y P. Heath (comps.)Immanuel Kant: Theoretical Philosophy After 1781, (pp. 337-424) New York: Cambridge University Press.

Kant, I. (2007). Critique of Judgment.Oxford :Oxford University Press.

Kerr, A. (2009). "Somos una raza privilegiada:" Anthropology, Race, and Nation in the Literature of the River Plate, 1870-2010 (Tesis doctoral inédita) Universidad de Virginia, EE.UU.

Kuhn, T.(1979).Metaphor in Science.En: A. Ortony (comp.) Metaphor and Thought. New York: Cambridge University Press.

Lakoff, G. yJohnson, M. (1980). Metaphors we live by. Londres:University of Chicago Press.

Le Roy Ladurie, E. (1978).Montaillou, village occitan de 1294 à 1324.Paris: Gallimard.

Lévi-Strauss, C. (1968). Introduction à I'œuvre de Marcel Mauss. En: M. Mauss, Anthropologie et sociologie, (pp. 9-44) Paris: Presses Universitaires Françaises.

Lindsay, C. (2011).Beyond Imperial Eyes. En: J. Edwards y R. Graulund. (comps.) Postcolonial Travel Writing. Londres: Palgrave Macmillan.

Lukacs, G.(1962). The Historical Novel, Londres: Merlin Press.

Lydon, J. y Rizvi, U. Z. (2010).Handbook of Postcolonial Archaeology.Walnut Creek:Left Coast Press.

Malinconico, D. (2012).The concept of philosophical archaeology in Kant and Foucault MetalogiconXXV, 51- 66.

Menard, A. (2008). "Escrituras Indígenas. Notas para la genealogía de un inverosímil", II Simposio Internacional de Estéticas Americanas (pp.253-267) Santiago de Chile:Pontificia Universidad Católica de Chile.

McQuillan, C. (2010). Philosophical Archaeology in Kant, Foucault, and Agamben. Parrhesia 10, 39-49.

Nagy, M.(2013).Los museos de la última frontera bonaerense y sus narrativas acerca de los pueblos indígenas. Revista del Museo de Antropología 6, 79-90.

Navarro Floria, P. (2006). Paisajes del progreso. La Norpatagonia en el discurso científico y político argentino de fines del siglo XIX y principios del XX. Scripta Nova. Revista electrónica de geografía y ciencias sociales, Vol. X, No 218 (76). http://www. 
ub.es/geocrit/sn/sn-218-76.htm. (Acceso: 15 diciembre 2019).

Navarro Floria, P. (2007). Paisajes de un progreso incierto. La Norpatagonia en las revistas científicas argentinas (1876-1909). En: Pedro Navarro Floria (ed.) Paisajes del progreso. La resignificación de la Patagonia Norte, 1880-1916.(pp. 13-77) Neuquén: Educo.

Olivier, L. (2008) Le Sombre Abime du Temps, Memoire et archaeologie, Paris: Seuil.

Olivier, L. (2012). Temps des vestiges et mémoire du passé: Traces, empreintes, palimpsestes En : S. A. de Beaune y H.-P. Francfort (eds.)L'archéologie à découvert: Hommes, objets, espaces et temporalités, (pp. 259-265) Paris : CNRS Éditions.

Paltrinieri, L.(2015) Archéologie. Le Télémaque 2 N 48, 15-30.

Parikka, J. y Hertz,G. (2010). CTheory Interview: Archaeologies of Media Art. Ctheory.net, http://ctheory.net/ctheory_wp/ ctheory-interview-archaeologies-of-media-art/ (Acceso: 20 diciembre 2019).

Park, S.M. (2014).The Pan American Imagination: Contested Visions of the Hemisphere in Twentieth-Century Literature, Charlottesville:University of Virginia Press.

Podgorny, I. (1999) Arqueología de la educación. Textos, indicios, monumentos. Buenos Aires: Sociedad Argentina de Antropologia.

Pratt, M.L. (2011).Ojos Imperiales. Literatura de viajes y transculturación. Buenos Aires: Fondo de Cultura Económica.

Quijada, M. (1996) Los 'incas arios'. Historia, lengua y raza en la construcción nacional hispanoamericana. Siglo XIX, Histórica18,2, 365-382.

Quijada, M. (1998) Ancestros, ciudadanos, piezas de museo. Francisco P. Moreno y la articulación del indígena en la construcción nacional argentina (siglo XIX). Estudios Interdisciplinarios de América Latina y el Caribe 9, 2, 21-46.

Quijada, M. (1999). La ciudadanización del"indio bárbaro". Políticas oficiales y oficiosas hacia la población indígena de La Pampa y la Patagonia, 1870-1920. Revista de Indias 59, 217, 675-704 http://revistadeindias.revistas.csic.es/index.php/ revistadeindias/article/view/832 (Acceso: 20 diciembre 2019).

Rathje, W y Murphy, C.(1992) Rubbish!: The Archaeology of Garbage; Nueva York: Harper Collins.

Rodríguez, M.E. De la "Extinción" a la Autoafirmación: procesos de visibilización de la comunidad tehuelche Camusu Aike (Provincia de Santa Cruz, Argentina). (Tesis doctoral inédita) Georgetown University, Washington DC, EEUU.

Rodríguez, M.E., Gerrard, A.C.y Vidal, M. (2018). A través de sus cenizas. Homenaje a Hernán Julio Vidal. Buenos Aires:Edición de las editoras.
Salgado, L., Navarro Floria, P. y Garrido, A.(2007)Huellas del mar en la tierra: los estudios de los antiguos terrenos marinos del territorio pampeano-patagónico y sus fósiles, 1824-1900. En: Pedro Navarro Floria (comp.)Paisajes del progreso. La resignificación de la Patagonia Norte, 1880-1916. (pp. 135190), Neuquén: Educo.

Salerno,V. y Pupio, A. (2009). Más allá de lo que se escribe: la arqueología como metáfora en los medios gráficos.Arqueología Suramericana /Arqueología sul-americana 5, 153-177.

San Martín, C. (2013). Sin país para los débiles: fueguinos arqueologizados enLa Australia Argentina de Payró. Estudios de Teoría Literaria 2. №3: 21-32.http://fh.mdp.edu.ar/revistas/ index.php/etl/index(Acceso: 20 diciembre 2019).

Scheinsohn, V. y Bellelli, C. (2018). Deconstruyendo el mito del antropólogo renacido. En: Rodríguez, M.E, Gerrard, A.C. y Vidal, M. (comps.)A través de sus cenizas. Homenaje a Hernán Julio Vidal (pp.203-234). Buenos Aires: Edición de las editoras.

Sluyter, A.(2006). Traveling/writing the unworld with Alexander von Humboldt.En: T. S. Terkenli y A.-M. d'Hauteserre (comp.) .Landscapes Of A New Cultural Economy Of Space(pp. 93-116).Berlin:Springer.

Teobaldo, M. y Nicoletti, M. A (2007).Representaciones sobre la Patagonia y sus habitantes originarios en los textos escolares: 1886-1940. Quinto Sol11,169-194.

Thomas, J (2004).Archaeology and Modernity, Londres: Routledge.

Thomas, J..(2009).Sigmund Freud's archaeological metaphor and archaeology's self-understanding. En: C. Holtorf y A. Piccini (comps.) Contemporary Archaeologies: Excavating Now(pp4168).,London:Peter Lang.

Trigger, B.(2006).A History of Archaeological Thought. Cambridge: Cambridge University Press.

Triggs, D.(2014).The Role of the Earth in Merleau-Ponty's Archaeological Phenomenology Chiasmi International 16, 255-273.

Vezub, J.(2009). Henry de La Vaulx en Patagonia (1896-1897): la historicidad escindida de la antropología colonial y la captura de corpus y cuerpos. Nuevo Mundo Mundos Nuevos; https:// doi.org/10.4000/nuevomundo.57810, (Acceso: 16 de marzo de 2020)

Vidal, H. (1993).A través de sus cenizas. Imágenes etnográficas e identidad regional en Tierra del Fuego (Argentina). (Tesis de Maestría inédita), Facultad Latinoamericana de Ciencias Sociales, Ecuador.

White, H. 1973.Metahistory: The Historical Imagination in Nineteenth-century Europe. Baltimore: Johns Hopkins University.

Zarankin, A y Acuto, F..(1999). Sed Non Satiata; Teoría Social en la Arqueología Latinoamericana Contemporánea, Buenos Aires: Del Tridente. 